\title{
Mechanism of Carrier Transport at Low Temperatures in n-Type beta-FeSi2/p-Type Si Heterojunctions Fabricated by Facing-Target Direct-Current Sputtering
}

\author{
Nathaporn Promros \\ Department of Physics, Faculty of Science \\ King Mongkut's Institute of Technology Ladkrabang \\ Bangkok, Thailand
}

Ryuji Baba

Department of Applied Science for Electronics and Materials Kyushu University

Kasuga, Fukuoka, Japan

Tarek M. Mostafa

Department of Applied Science for Electronics and Materials Kyushu University

Kasuga, Fukuoka, Japan

\begin{abstract}
The fabrication of n-type $\beta$ - $\mathrm{FeSi}_{2} / \mathrm{p}$-type $\mathrm{Si}$ hetero junctions was accomplished by FTDC Sat a substrate temperature of $600^{\circ} \mathrm{Cwithout}$ post-annealing. Their currentvoltage characteristic curves were measured at low temperatures ranging from $300 \mathrm{~K}$ down to $50 \mathrm{~K}$. In order to examine the mechanism of carrier transport in the hetero junctions using thermionic emission theory, the ideality factor was estimated from the slope of the linear part of forward $\ln J-\mathrm{V}$ characteristic curves. In the temperature range from $300 \mathrm{~K}$ down to $225 \mathrm{~K}$, the ideality factor was 1.23 at $300 \mathrm{~K}$ and increased to 2.02 at $225 \mathrm{~K}$. The ideality factor values $\leq 2$ implied that the mechanism of carrier transport was governed by a recombination process. In the temperature range from $200 \mathrm{~K}$ down to $50 \mathrm{~K}$, the ideality factor was 3.34 at $200 \mathrm{~K}$ and increased to 15.56at $50 \mathrm{~K}$. Parameter A was calculated to be constant. The temperature dependent ideality factor, together with the constant value of parameter $A$, implied that the predominant mechanism of carrier transport was a trap-assisted multi-step tunneling process. At highly applied forward bias voltage, the mechanism of carrier transport was changed to a space charge limited current process.
\end{abstract}

Keywords-iron disilicide; FTDCS; heterojunction; I-V characteristic; carrier transport

\section{INTRODUCTION}

At present, semiconducting iron disilicide $(\beta-\mathrm{FeSi} 2)$ is a promising candidate for integration with silicon for optoelectronic applications because of its remarkable electrical and optical properties [1-2].It possesses a high optical absorption coeffcient greater than $105 \mathrm{~cm}-1$ at $1.2 \mathrm{eV}$ and a direct optical band gap of $0.85 \mathrm{eV}$ above an indirect optical

\author{
Motoki Takahara \\ Department of Applied Science for Electronics and Materials \\ Kyushu University \\ Kasuga, Fukuoka, Japan \\ Mahmoud Shaban \\ Department of Electrical Engineering \\ South Valley University \\ Aswan, Egypt \\ Tsuyoshi Yoshitake \\ Department of Applied Science for Electronics and Materials \\ Kyushu University \\ Kasuga, Fukuoka, Japan
}

band gap of $0.74 \mathrm{eV}$.The values of band gap correspond to optical fiber telecommunication wave lengths ranging from 1.31 to $1.55 \mu \mathrm{m}$ [3].Moreover, $\beta-\mathrm{FeSi} 2$ thin films can be grown epitaxial yon $\mathrm{Si}$ substrates with small lattice mismatches (2-5\%) [3].It is also an ecologically friendly material because of the non toxicity of its component elements ( $\mathrm{Si}$ and $\mathrm{Fe}$ ) [4].

Previously, the epitaxial growth of $\beta-\mathrm{FeSi} 2$ on $\mathrm{Si}(111)$ substrates was realized by facing-target direct-current sputtering (FTDCS) at a substrate temperature of600 oC without post-annealing[5]. This substrate temperature was 200 oC lower than general post-annealing temperatures.Our $\beta$ FeSi2thin films exhibited n-type conduction with a carrier concentration ranging between 1017 and $1018 \mathrm{~cm}-3$. n-Type $\beta$ $\mathrm{FeSi} 2 / \mathrm{p}$-type Si hetero junctions that showed good rectifying actions were employed as photodiodes [4].Then, it was confirmed that their photo detection performances were enhanced at low temperatures [5]. However, their carrier transport mechanism at low temperatures has never been studied. In this study, n-type $\beta$-FeSi2/p-type Si hetero junctions were fabricated by FTDCS and their current-voltage (IV)characteristics were measured at low temperatures ranging from $300 \mathrm{~K}$ down to $50 \mathrm{~K}$. Their carrier transport mechanisms were examined using thermionic emission theory. It was demonstrated that a recombination process was the predominant mechanism of carrier transport at temperatures ranging from $300 \mathrm{~K}$ down to $225 \mathrm{~K}$ and changed to a trapassisted multi-step tunneling process at temperatures ranging from $200 \mathrm{~K}$ down to $50 \mathrm{~K}$. At highly applied forward bias 
voltage, a space charge limited current process was the predominant mechanism of carrier transport.

\section{EXPERIMENTAL DETAILS}

$\mathrm{n}$-Type $\beta$-FeSi2 films, with a thickness of $300 \mathrm{~nm}$, were grown epitaxial on p-type $\mathrm{Cz}-\mathrm{Si}(111)$ substrates at $600{ }^{\circ} \mathrm{C}$ by FTDCS using FeSi2 alloy targets (purity: 4N). The substrates were immersed in diluted hydrofluoric acid solution (HF concentration: $1 \%$ ) in order to remove their native oxide layers and then rinsed in deionized water before being mounted into a FTDCS chamber. The targets and substrates in the FTDCS chamber were separated by a distance of $75 \mathrm{~mm}$ and the chamber was evacuated to a base pressure less than $3 \times 10-5 \mathrm{~Pa}$. During the sputtering process, Ar gas (purity: 6N) was introduced to the chamber at a flow rate of $15 \mathrm{sccm}$. The sputtering pressure was maintained at a constant $1.33 \times 10-1 \mathrm{~Pa}$. The plasma DC voltage and current were $1 \mathrm{kV}$ and $1.5 \mathrm{~mA}$, respectively. Using a radiofrequency magnetron sputtering apparatus equipped with a separated load lock exchange chamber, a finger-shaped Pd electrode was deposited on the front $\mathrm{Si}$ surface and an $\mathrm{Al}$ electrode was deposited on the back $\beta$-FeSi2 surface.

The crystalline structure was characterized by XRD (Rigaku, RINT 2000/PC) analysis using $\mathrm{Cu}-\mathrm{K} \alpha$ radiation. The $\mathrm{I}-\mathrm{V}$ characteristics of the hetero junctions were measured in the dark at low temperatures ranging from $300 \mathrm{~K}$ down to50 Kusing a source meter (Keithley 2400).Using thermionic emission theory, the ideality factor was estimated from the slope of the linear part from the forward $\ln \mathrm{J}-\mathrm{V}$ characteristic curves.

\section{RESUlTS AND DiscUSSION}

Figure I displays the XRD patterns measured in (a) $2 \theta-\theta$ scan and (b) $2 \theta$ scan with an incidence angle of $4^{\circ}$ of the $\beta$ FeSi2films. A strong 202/220 peak and a weak 404/440 peak, which were typical XRD peaks of the $\beta$-FeSi2 thin films grown epitaxiallyon $\mathrm{Si}(111)$, were observed evidently in the $2 \theta-\theta$ pattern. The $2 \theta$ XRD pattern exhibited no peaks. This result implied that polycrystalline $\beta$-FeSi2 existed sparingly. Figure 1 (c) shows the pole figure concerning $\beta-440 / 404$ peak. This indicated that three types of epitaxial variant were rotated at an angle of $120^{\circ}$ with respect to each other [5]. These results confirmed that the $\beta-\mathrm{FeSi} 2$ film was grown epitaxiallynot just in a direction perpendicular to the film plane, but also in-plane on $\operatorname{Si}(111)$ substrate.

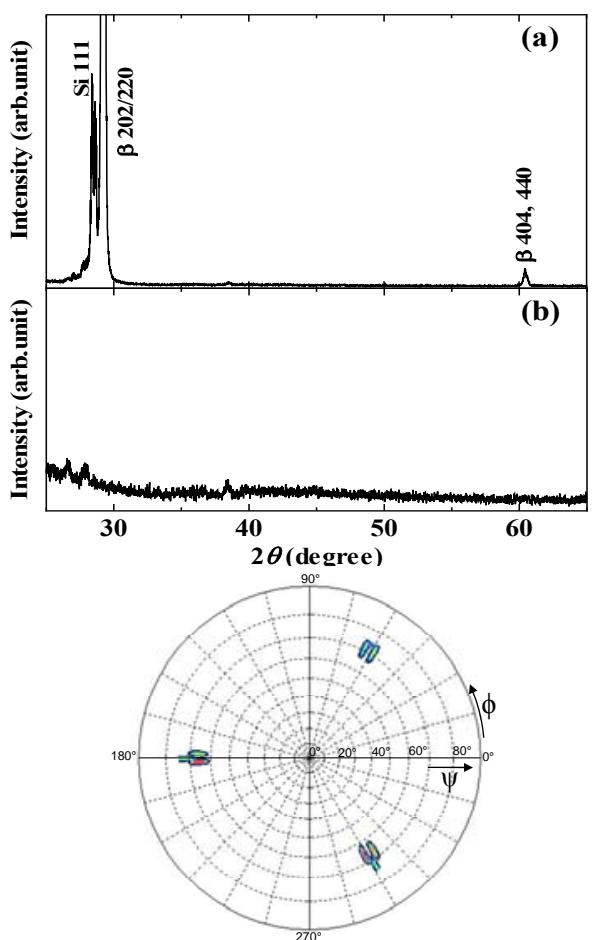

(c)

FIGURE I. $2 \Theta-\Theta$, (b) $2 \Theta$ XRD PATTERNS OF B-FESI2 THIN FILMS DEPOSITED ON SI(111) SUBSTRATE AND (c) POLE FIGURE CONCERNING THE $\beta-440 / 404$ DIFFRACTION PEAK

Figure II displays the dark reverse and forward J-V characteristic curves measured in the temperature ranging from $300 \mathrm{~K}$ to $50 \mathrm{~K}$. The hetero junctions exhibited a good rectifying action with a rectification ratio between the forward and reverse currents at bias voltages of $\pm 1 \mathrm{~V}$ of higher than two orders of magnitude. The leakage current was reduced dramatically with a decrease in temperature. This suppression should be attributed predominantly to the reduced carrier densityin $\beta-F e S i 2$ film sat low temperatures $[2,4]$.

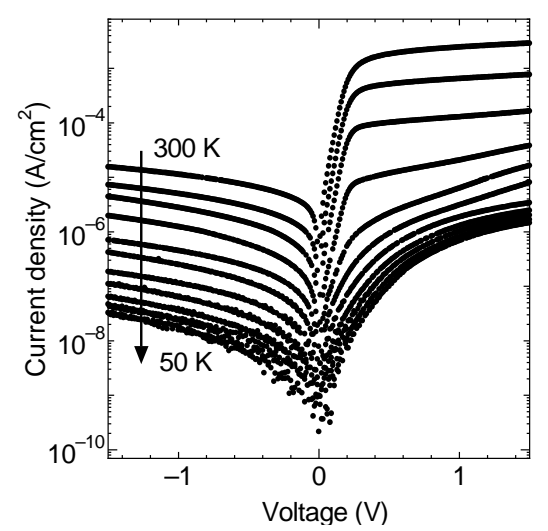

FIGURE II. TYPICAL DARK J-V CHARACTERISTIC CURVES OF HETEROJUNCTIONS MEASURED AT LOW TEMPERATURES RANGINGFROM 300 KDOWN TO50 K 
According to the significant difference in the carrier concentration between our $\beta$-FeSi2 films $(\sim 1018 \mathrm{~cm}-3)$ and $\mathrm{Si}$ substrates $(\sim 1015 \mathrm{~cm}-3)$ [5], it can be assumed that the hetero junctions acted almost as a step junction. Therefore, the current flowing through the hetero junctions can be described based on thermionic emission theory as follows [6-7]:

$$
\mathrm{J}=\mathrm{J}_{0}\left[\exp \left(\frac{\mathrm{qV}}{\mathrm{nkT}}\right)-1\right](1)
$$

Where J0,V, q, k, Tandn are the saturation current density, applied forward bias voltage, unit charge, Boltzmann's constant, absolute temperature and ideality factor. From Eq. (1), the ideality factor was estimated from the slope of the linear part from the forward $\ln \mathrm{J}-\mathrm{V}$ characteristic curves using the relation:

$$
\mathrm{n}=\frac{\mathrm{q}}{\mathrm{kT}} \frac{\mathrm{dV}}{\mathrm{d}(\ln \mathrm{J})}
$$

Figure 3displays the temperature dependence of the ideality factor analyzed from the forward $\mathrm{lnJ}-\mathrm{V}$ characteristic curves. At $300 \mathrm{~K}$, the ideality factor was 1.23 and increased to 2.02 at $225 \mathrm{~K}$. Ideality factor values $\leq 2$ implied that the mechanism of carrier transport was governed by a recombination process in the $\beta$-FeSi2 layer and at the hetero junction interface [8].The defects in the $\beta-\mathrm{FeSi} 2$ layer might form a deep energy level in the band gap, which could act as a recombination center. At $200 \mathrm{~K}$, the ideality factor was 3.34 and increased to 15.56 at 50 $\mathrm{K}$. Ideality factor values $>2$ implied that the tunneling process contributed to the mechanism of carrier transport [8]. This should be attributed to the existence of interface states at the junction interface and the localized electronic states in the $\beta$ $\mathrm{FeSi} 2$ layer.

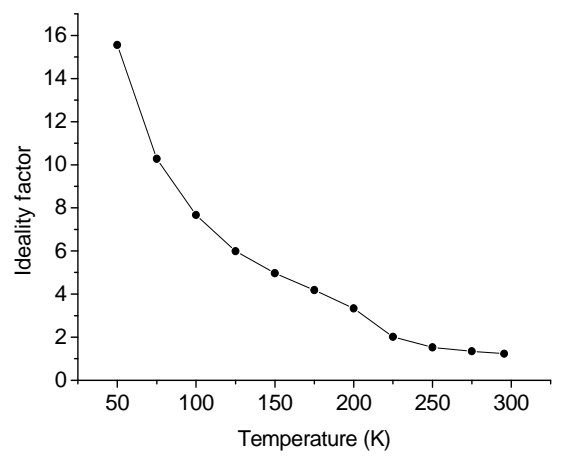

FIGURE III. A PLOT OF IDEALITY FACTOR AS A FUNCTION OF TEMPERATURE

To determine the mechanism of carrier transport in the hetero junctions, the $\mathrm{J}-\mathrm{V}$ relationship is written as $[6,8]$ :

$$
\mathrm{J}=\mathrm{J}_{0}(\mathrm{~T}) \exp (\mathrm{VA})
$$

The mechanism of carrier transport in the hetero junctions can be determined from parameter A. It can be estimated using the relation $\mathrm{A}=\mathrm{q} / \mathrm{nkT}$ and $\mathrm{A}=$ constant for a tunneling mechanism. Figure 4displays a plot of parameter A versus temperature. From this plot, the value of parameter A was nearly constant at low temperatures ranging from $200 \mathrm{~K}$ down to $50 \mathrm{~K}$. The constant value of parameter A, together with the temperature dependent ideality factor, indicated that the mechanism of carrier transport was governed by a trap-assisted multi-step tunneling process in the hetero junctions [9-10].

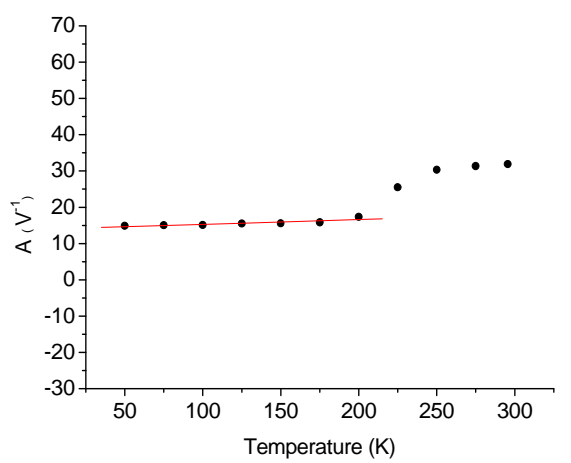

\section{FIGURE IV. A PLOT OF PARAMETER A VERSUS TEMPERATURE}

At highly applied forward bias voltage, the $\ln J-\mathrm{V}$ characteristic curves became nonlinear. This implied that the predominant mechanism of carrier transport in the hetero junctions was changed to another mechanism, such as space charge limited current process. Based on this process, the relation between current density and applied bias voltage is written as [10]:

$$
\vartheta=\varsigma \mu
$$

Where parameter $\mathrm{m}$ is a constant greater than 2 .

Figure 5 displays the typical forward $\log \mathrm{J}-\log \mathrm{V}$ characteristic curves of hetero junctions at $300 \mathrm{~K}, 200 \mathrm{~K}$ and 50 $\mathrm{K}$. At highly applied forward bias voltage, the parameter $\mathrm{m}$ values calculated from the slopes of $\log \mathrm{J}-\log \mathrm{V}$ characteristic curves were greater than 2 . It was expected that the mechanism of carrier transport in the hetero junctions was governed by a space charge limited current process.

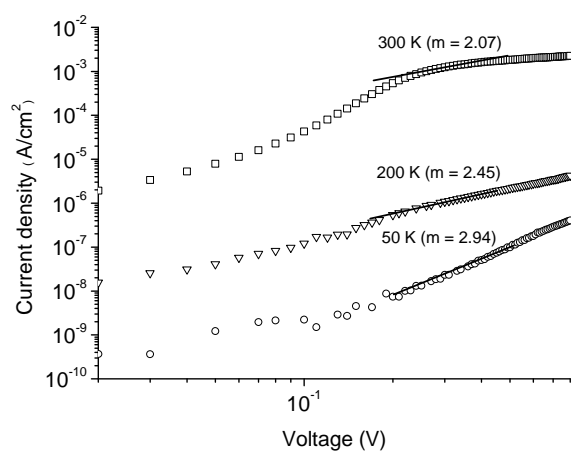

FIGURE V. TYPICAL FORWARD LOGJ-LOGV CHARACTERISTIC CURVES AT 300K, 200K AND $50 \mathrm{~K}$ 


\section{SUMMARY}

n-Type $\beta$-FeSi2/p-type Si hetero junctions were fabricated by FTDC Sat a substrate temperature of $600^{\circ} \mathrm{C}$.Their I-V characteristics were measured at low temperatures ranging from $300 \mathrm{~K}$ down to $50 \mathrm{Kin}$ order to examine the mechanism of carrier transport using thermionic emission theory. As temperature decreased from $300 \mathrm{~K}$ to $225 \mathrm{~K}$, a recombination process was the dominant mechanism of carrier transport in the hetero junctions. At temperatures below $225 \mathrm{~K}$, the strong temperature dependence of ideality factor, together with the constant value of parameter A, implied that a trap- assisted multi-step tunneling process was the dominant mechanism of carrier transport. At highly applied forward bias voltage, the mechanism of carrier transport was changed to a space charge limited current process.

\section{REFERENCES}

[1] N. Promros, K. Yamashita, R. Iwasaki, and T. Yoshitake, Effects of Hydrogen Passivation on Near-Infrared Photodetection of n-Type $\beta$ $\mathrm{FeSi}_{2} / \mathrm{p}$-Type $\mathrm{Si}$ Heterojunction Photodiodes, Jpn. J. Appl. Phys. 51(2012)108006-1 - 108006-2.

[2] N. Promros, K. Yamashita, S. Izumi, R. Iwasaki, M. Shaban, and T. Yoshitake, Near-Infrared Photodetection of n-Type $\beta-\mathrm{FeSi}_{2} /$ Intrinsic $\mathrm{Si} / \mathrm{p}$-Type Si Heterojunctions at Low Temperatures, Jpn. J. Appl. Phys. 51(2012)09MF02-1 - 09MF02-4.

[3] M. Shaban, K. Nomoto, S. Izumi, and T. Yoshitake, Characterization of near-infrared n-type $\beta$ - $\mathrm{FeSi}_{2} / \mathrm{p}$-type $\mathrm{Si}$ heterojunction photodiodes at room temperature, Appl. Phys. Lett. 94 (2009) 222113-1 - 222113-3.

[4] S. Izumi, M. Shaban, N. Promros, K. Nomoto, and T. Yoshitake, Nearinfrared photodetection of $\beta-\mathrm{FeSi}_{2} / \mathrm{Si}$ heterojunction photodiodes at low temperatures, Appl. Phys. Lett.102 (2013) 032107 -1 - 032107-4.

[5] T. Yoshitake, Y. Inokuchi, A. Yuri, and K. Nagayama, Direct epitaxial growth of semiconducting $\beta-\mathrm{FeSi}_{2}$ thin films on $\mathrm{Si}(111)$ by facing targets direct-current sputtering, Appl. Phys. Lett. 88 (2006) 182104-1 182104-3.

[6] F.OzyurtKus, T.Serin, and N. Serin, Current transport mechanisms of n$\mathrm{ZnO} / \mathrm{p}-\mathrm{CuOheterojunctions,} \mathrm{J.} \mathrm{Optoelectron.} \mathrm{Adv.} \mathrm{M.} 11$ (2013) 1855 1859.

[7] H. S. Hafez, I. S. Yahia, G. B. Sakr, M. S. A. Abdel-Mottaleb, and F. Yakuphanoglu, Extraction of the DSSC parameters based $\mathrm{TiO}_{2}$ under dark and illumination conditions, Adv. Mater. Corros. 1 (2012) 8 - 13.

[8] D. Song, and B. Guo, Electrical properties and carrier transport mechanisms of $\mathrm{n}-\mathrm{ZnO} / \mathrm{SiO}_{\mathrm{x}} / \mathrm{n}-\mathrm{Si}$ isotype heterojunctions with native or thermal oxide interlayers, J. Phys. D: Appl. Phys. 42(2009) 025103-1 025103-8.

[9] T. Serin, S. Gurakar, N. Serin, N. Yildirim, and F. Ozyurt Kus, Current flow mechanism in $\mathrm{Cu}_{2} \mathrm{O} / \mathrm{p}-\mathrm{Si}$ heterojunction prepared by chemical method, J. Phys. D: Appl. Phys. 42 (2009) 225108-1 - 225108-5.

[10] L. F. Marsai, I. Martin, J. Pallares, A. Orpella, and R. Alcubilla, Annealing effects on the conduction mechanisms of $p^{+}$-amorphous$\mathrm{Si}_{0.8} \mathrm{C}_{0.2}: \mathrm{H} / n$-crystalline-Si diodes, J. Appl. Phys. 94 (2003) 2622 - 2626. 